\title{
Synthesis of pyrene-based Fe(II)-complex and its photovoltaic properties
}

\author{
Erdoğan M. ${ }^{1}$, Demirci S. ${ }^{2}$, Adıgüzel V. ${ }^{2}$, Horoz S. ${ }^{3}$ and Sait İzgi M. ${ }^{4}$ \\ ${ }^{1}$ Kafkas University, Faculty of Engineering and Architecture, Department of Food Engineering, Kars, 36100, Turkey \\ ${ }^{2}$ Kafkas University, Faculty of Engineering and Architecture, Department of Chemical Engineering, Kars, 36100, Turkey \\ ${ }^{3}$ Siirt University, Faculty of Engineering, Department of Electrical and Electronics Engineering, Siirt, 56100, Turkey \\ ${ }^{4}$ Siirt University, Faculty of Engineering, Department of Chemical Engineering, Siirt, 56100, Turkey \\ Received: 06/06/2021, Accepted: 13/09/2021, Available online: 26/10/2021 \\ *to whom all correspondence should be addressed: e-mail: sabithoroz@siirt.edu.tr \\ https://doi.org/10.30955/gnj.003754
}

\section{Graphical abstract}
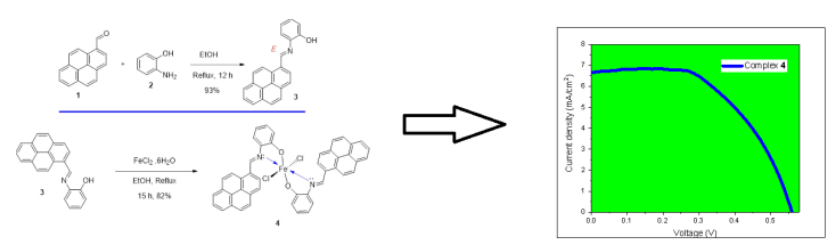

\section{Abstract}

(E)-2-((pyren-1-ylmethylene)amino)phenol (3) containing pyrene linked through an imine bond to a phenol unit was synthesized and its Fe-complex 4 was prepared. The complex $\mathbf{4}$ is characterized by infrared (IR), x-ray diffraction (XRD) and UV-Vis spectroscopy techniques. The synthesized complex was used as a sensitizer in a solar cell structure. From the current density (J)-voltage (V) curve obtained, the values of the short-circuit current density $\left(\mathrm{J}_{\mathrm{SC}}\right)$, maximum current density $\left(\mathrm{J}_{\mathrm{M}}\right)$, open-circuit voltage $\left(V_{o c}\right)$ and maximum voltage $\left(V_{M}\right)$ for the complex 4 were determined as $6.68 \mathrm{~mA} / \mathrm{cm}^{2}, 4.73 \mathrm{~mA} / \mathrm{cm}^{2}, 0.56 \mathrm{~V}$ and 0.41 $\mathrm{V}$, respectively. Using these parameters, the fill factor (FF) and power conversion efficiency value $(\eta)$ of complex 4 were calculated as 0.52 and 1.94 , respectively. This value shows that complex $\mathbf{4}$ can be used as an effective sensitiser in solar cell applications.

Keywords: Pyrene; photovoltaic; imine; Fe (II) complex.

\section{Introduction}

Pyrene-based compounds are used in order to scan living cell by using their colorimetric and fluorescent characteristics as an optical sensor and as a chemoreceptor (Kushwaha et al., 2018; Pinheiro et al., 2014; Rasheed et al., 2015; Shellaiah et al., 2013; Tümay et al., 2018). Pyrene is also used as a chemical sensor to detect chemicals such as neutral molecules, organic molecules, anionic and cationic analytes (Pinheiro et al., 2014). Schiff bases include azomethine group $(\mathrm{C}=\mathrm{N})$ in their structures. They provide high coordination with the transition metals due to a pair of electrons orbiting the $\mathrm{sp}^{2}$ hybrid of the $\mathrm{N}$ atom of this azomethine group (Altuntas et al., 2021; Şahin et al., 2020). Moreover, they are organic compounds that have an important place in the development of coordination chemistry because they form highly stable complexes (Erdoğan et al., 2021; Güngördü Solğun et al., 2018; Horoz et al., 2018; Kapıcıoğlu et al., 2020). Schiff base Fecomplexes, with due to high stability in different oxidation states, have a wide range of applications such as in industry, as catalysis in chemistry, as antifungal, antibacterial, antitumor and anticancer in biology, and pharmacology (Abdel-Rahman et al., 2017; Haghverdi et al., 2018, Joseph and Rani, 2017; Mahmoud et al., 2018; Prasad et al., 2019).

Dye-sensitized solar cells (DSSCs) are a cheaper alternative to the traditional semiconductor-based, crystalline solar cells due to their low manufacturing cost (Clifford et al., 2011; Nazeeruddin et al., 1993). Unlike traditional solar cells, the dye that is responsible for the light absorption process in DSSCs is isolated from the components involved in transporting carriers of charges (Clifford et al., 2011). It was used many" Ru(II)-polypyridins as sensitizers in DSSCs, achieving system efficiencies of more than 10\% (Chen et al., 2009; Kalyanasundaram and Grätzel, 1998; Nazeeruddin et al., 1993). Substituting $\mathrm{Ru}(\mathrm{II})$ with environmentally friendly and earth-abundant $\mathrm{Fe}(\mathrm{II})$ in the polypyridyl dye will further reduce the cost of DSSCs. Ferrere and Gregg first showed the ability of Fe(II)polypyridins to photosensitize $\mathrm{TiO}_{2}$ in a system where dye is attached to $\mathrm{TiO}_{2}$ through the carboxylic acid linker (Ferrere and Gregg, 1998). This mechanism displays bandselective sensitization from the originally excited shortlived metal to ligand charge transfer (MLCT) state, suggesting that sensitization is feasible even for complexes that lack long-lived excited photoactive state. The effect of solvent and various substituents on the absorption properties of $\mathrm{TiO}_{2}$ was subsequently observed, showing that a carboxylic acid linker paires the dye to $\mathrm{TiO}_{2}$ more efficiently than a phosphonic acid linker. In Fe complex$\mathrm{TiO}_{2}$ assemblies, Meyer et al. demonstrated mainly two 
sensitization frameworks: (1) direct sensitization in which an electron is induced from the Fe(II) core directly into $\mathrm{Ti}(\mathrm{IV})$ sites on $\mathrm{TiO}_{2}$ and (2) indirect sensitization concerning inter - facial electron transfer (IET) from the originally populated dye MLCT states into the $\mathrm{TiO}_{2}$ conduction band (Yang et al., 2000).

In this study, azomethine bridged pyrene phenol-based ligand is obtained from the reaction of pyrene aldehyde and 2-aminophenol. After the obtained ligand is characterized, Fe (II) complex is synthesized. The photovoltaic characteristics of this complex are examined.

\section{Experimental}

\subsection{General remarks}

All reactions were carried out under nitrogen and monitored by TLC. All solvents were dried and distilled before use. TLC was carried out on silica gel 60 HF254 aluminium plates (Fluka). Melting points are uncorrected. The one- and two-dimensional NMR spectra were recorded on a Bruker-400 spectrometer using tetramethylsilane as the internal reference. The NMR spectra were recorded at $25{ }^{\circ} \mathrm{C}$ and coupling constants ( $\mathrm{J}$ values) are given in $\mathrm{Hz}$. Chemical shifts are given in parts per million (ppm). IR spectra were recorded on Perkin Elmer FT-IR spectrometer. Absorption spectrometry was performed using a Perkin Elmer Lambda 35 spectrophotometer. Absorbance spectroscopy measurement was performed on $5 \mu \mathrm{M}$ samples in $\mathrm{CH}_{2} \mathrm{Cl}_{2}$. The method we reported in our previous study was used for J-V measurements. The suspension of the complex 4 was used as the sensitizer (Erdoğan and Horoz, 2021).

\subsection{Preparation of ligand 3}

The ligand $\mathbf{3}$ were synthesized according to a previously reported method in the literature (Rasheed et al., 2015).

Pyrene-1-carbaldehyde (1): ${ }^{1} \mathrm{H} \mathrm{NMR}\left(400 \mathrm{MHz}, \mathrm{CDCl}_{3}\right) \delta$ $10.77(\mathrm{~s}, 1 \mathrm{H}), 9.41(\mathrm{~d}, J=9.4 \mathrm{~Hz}, 1 \mathrm{H}), 8.43(\mathrm{~d}, J=8.0 \mathrm{~Hz}, 1 \mathrm{H})$, 8.32-8.27 (m, 3H), 8.26-8.19 (m, 2H), 8.14-8.03 (m, 2H). (see the Supplementary Material for details, Figure S1).

(E)-2-((Pyren-1-ylmethylene)amino)phenol (3): ${ }^{1} \mathrm{H} \quad \mathrm{NMR}$ (400 MHz, $\left.\mathrm{CDCl}_{3}\right) \delta 9.75(\mathrm{~s}, 1 \mathrm{H}$, imine $\underline{\mathrm{H}}-\mathrm{C}=\mathrm{N}), 8.87(\mathrm{~d}, J=$ $9.4 \mathrm{~Hz}, 1 \mathrm{H}), 8.79(\mathrm{~d}, J=8.1 \mathrm{~Hz}, 1 \mathrm{H}), 8.31-8.01(\mathrm{~m}, 7 \mathrm{H}), 7.49$ $(\mathrm{dd}, J=7.9, J=1.2 \mathrm{~Hz}, 1 \mathrm{H}), 7.42(\mathrm{~s}, 1 \mathrm{H}, \mathrm{OH}), 7.30-7.23(\mathrm{~m}$, $1 \mathrm{H}), 7.09$ (dd, $J=8.1, J=1.1 \mathrm{~Hz}, 1 \mathrm{H}$ ), 7.04-6.97 (m, 1H). (see the Supplementary Material for details, Figure S2). IR ( $\mathrm{cm}^{-}$ $\left.{ }^{1}\right)$ : $V_{\max } 3357,3065,3042,3024,2987,1612,1589,1575$, $1537,1489,1388,1362,1289,1246,1185,1151,848,821$, $744,713$.

\subsection{Preparation of $\mathrm{Fe}(\mathrm{II})$-complex 4}

A solution of the ligand 3 (0.994 g, $3.090 \mathrm{mmol})$ in dry EtOH $(30 \mathrm{~mL})$ was added to a stirred solution of a mixture of $\mathrm{FeCl}_{2} .6 \mathrm{H}_{2} \mathrm{O}(0.300 \mathrm{~g}, 1.510 \mathrm{mmol})$ in distilled $\mathrm{EtOH}(10 \mathrm{~mL})$ under $\mathrm{N}_{2}$ atm. The resulting reaction mixture was heated for $15 \mathrm{~h}$ at reflux temperature. After being cooled to room temperature, the precipitate formed was filtered and washed several times with hot $\mathrm{EtOH}$ to give black solid complex 4 (yield $0.950 \mathrm{~g}, 82 \%$ ). IR $\left(\mathrm{cm}^{-1}\right)$ : $v_{\max } 3006,2989$, $1575,1474,1392,1275,1261,1233,844,764,750,710$.

\section{Results and discussion}

\subsection{Synthesis}

Pyrene-1-carbaldehyde (1), which was commercially available, became the key structure that allowed us to prepare ligand 3. As shown in Scheme 1, ligand 3 was synthesized according to a previously reported method via a one pot pyrene-1-carbaldehyde (1) and 2-aminophenol (2) condensation in ethanol with excellent yield (93\%) (Rasheed et al., 2015). Then, the complex 4 was obtained in one step from the ligand $\mathbf{3}$ ( 2 equiv.) by treatment with $\mathrm{FeCl}_{2} .6 \mathrm{H}_{2} \mathrm{O}$ (1 equiv.) under refluxing dry EtOH for $15 \mathrm{~h}$ in $82 \%$ yield (Scheme 1 ).

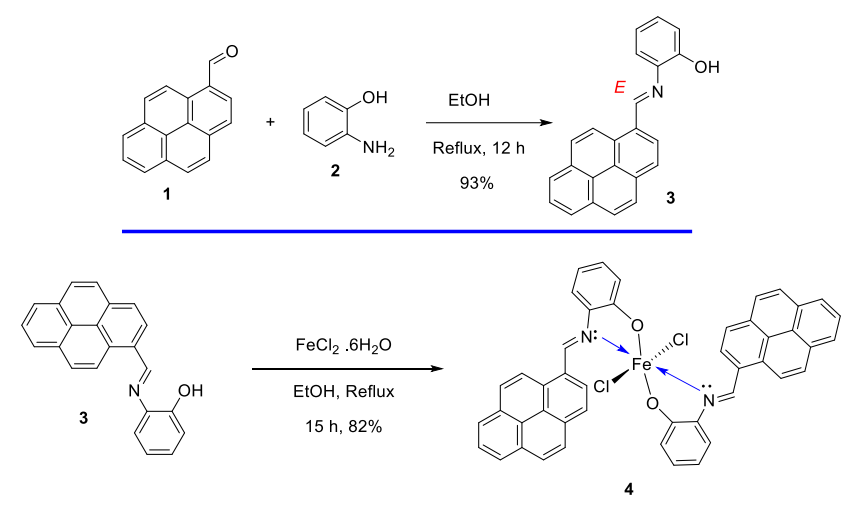

Scheme 1. Route of synthesis of Fe (II)-complex 4.

\subsection{FT-IR analysis}

The IR spectrum of ligand $\mathbf{3}$ exhibited characteristic absorptions bands for $-\mathrm{OH}$ functional group, aromatic $-\mathrm{C}-\mathrm{H}$, imine $-\mathrm{C}=\mathrm{N}-$, and aromatic $-\mathrm{C}=\mathrm{C}$ - bonds and no peaks attributable to unreacted amine or carbonyl groups (starting materials) were found.

The $\mathrm{O}-\mathrm{H}$ stretch in phenolic unit is observed at $3357 \mathrm{~cm}^{-1}$. The absorption bands at 2987, 3024 and $3042 \mathrm{~cm}^{-1}$ are attributed to aromatic $\mathrm{C}-\mathrm{H}$ bending vibrations of compound 3 . The absorption band at $1612 \mathrm{~cm}^{-1}$ is assigned to stretching vibrations of the imine functional group, and those at 1589, 1575, 1537 and $1489 \mathrm{~cm}^{-1}$ are due to the aromatic $\mathrm{C}=\mathrm{C}$ groups (see the Supplementary Material for details, Figure S3).

The IR spectrum of complex $\mathbf{4}$ exhibited characteristic absorptions bands for aromatic $\mathrm{C}-\mathrm{H}$, and aromatic $\mathrm{C}=\mathrm{C}$ bonds. The absorption bands at 3006 and $2989 \mathrm{~cm}^{-1}$ are attributed to aromatic $\mathrm{C}-\mathrm{H}$ bending vibration of the complex 4. The absorption band at 1474 and $1575 \mathrm{~cm}^{-1}$ are assigned to the stretching vibration of the aromatic $\mathrm{C}=\mathrm{C}$ groups. It was observed that the signal of the $-\mathrm{OH}$ functional group was disappeared (see the Supplementary Material for details, Figure S4).

\subsection{UV-vis and XRD analysis}

The result of the absorbance measurement for the complex 4 is shown in Figure 1. The UV-vis absorption spectra of the complex 4, in $\mathrm{CH}_{2} \mathrm{Cl}_{2}(5 \mu \mathrm{M})$ are dominated by absorption bands at the ligand 3; 229, 233, 296 and 413, the complex 4; 234, 289, 378, and $398 \mathrm{~nm}$. As seen in Figure 1, the ligand 3 showed characteristic pyrene absorption peaks with their vibrational features. A peak observed at around $233 \mathrm{~nm}$ in the ligand $\mathbf{3}$ is attributed to $\pi \rightarrow \pi^{*}$ transition in the 
aromatic rings, which remains almost unchanged in the metal complexes (234 nm).

Especially, a small hump observed in the region of 418-420 $\mathrm{nm}$ in the $\mathrm{Fe}$ (II) complex 4. It may be the result of charge transfer from the imine nitrogen atom or oxygen atoms to the metal centre (Joseph and Rani, 2014).

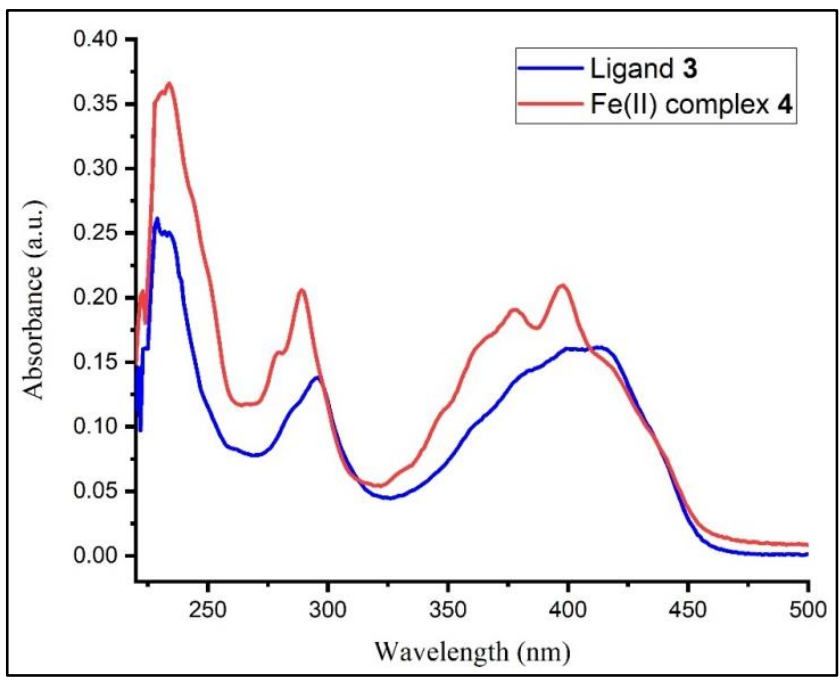

Figure 1. Plot of the wavelength versus absorbance intensity for complex 4.

To obtain further information on the structure of the complex 4, X-ray powder (XRD) diffraction was performed. The XRD patterns of the complex $\mathbf{4}$ is given Figure 2 . As seen from the figure, the patterns are typical of amorphous structure of Fe-complex. Similiar result was reported by Zou et al. (2018).

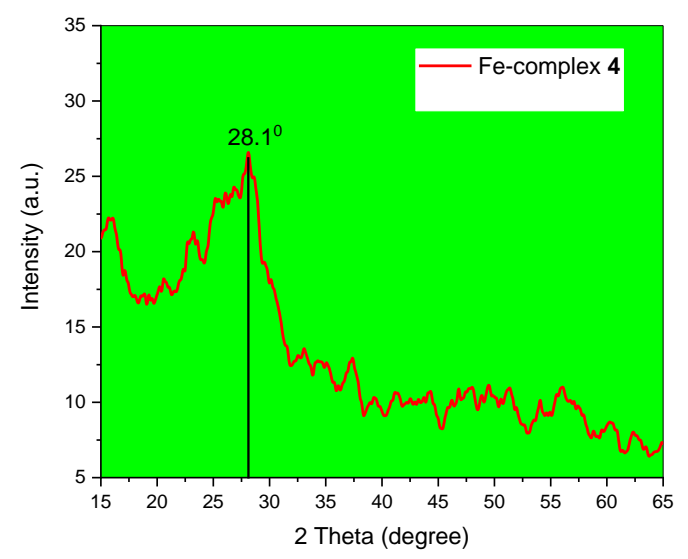

Figure 2. The XRD diffraction patterns of Fe(II) complex.

\subsection{J-V measurement}

Figure 3 shows the J-V curve of the synthesized complex 4 . Based on the J-V curve obtained, the values of the shortcircuit current density ( $\left.\mathrm{J}_{\mathrm{sc}}\right)$, maximum current density $\left(\mathrm{J}_{\mathrm{M}}\right)$, open-circuit voltage $\left(V_{O C}\right)$ and maximum voltage $\left(V_{M}\right)$ for the complex 4 were determined as $6.68 \mathrm{~mA} / \mathrm{cm}^{2}, 4.73$ $\mathrm{mA} / \mathrm{cm}^{2}, 0.56 \mathrm{~V}$ and $0.41 \mathrm{~V}$, respectively. Using the equations (Eq.1 and Eq.2) given below (Şahin et al., 2020), the fill factor (FF) and power conversion efficiency value ( $\eta$ ) of complex 4 were calculated as 0.52 and 1.94, respectively.

$$
\begin{gathered}
F F=\frac{P_{m}}{J_{s c} V_{o c}}=\frac{J_{M} V_{M}}{J_{s c} V_{o c}} \\
\eta=\frac{P_{m}}{P_{i n}}=\frac{J_{s c} V_{o c} F F}{P_{i n}}
\end{gathered}
$$

where $P_{m}$ : maximum output power density, $P_{i n}$ : power density of incoming light.

It is well known that $\eta \%$ value of a DSSC device can be affected by the rate of electron transport in a solar cell structure. The obtained high Jsc value for complex 4 indicates that there is an effective injection of electrons into $\mathrm{TiO}_{2}$ conduction band from excited state of complex dye. Thus, this leads to obtain improved conversion efficiency for complex 4 based-solar cell structure.

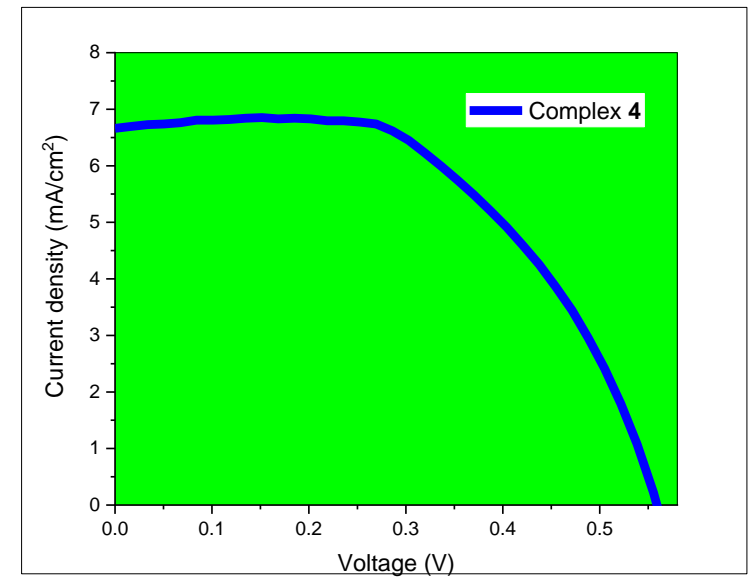

Figure 3. J-V curve of the complex 4.

\section{Conclusions}

In summary, with azomethine bridge, a pyrene-phenol based ligand 3, and its Fe-complex $\mathbf{4}$ were synthesized and characterized using spectroscopic methods. The complex was synthesized in good yield by simple condensation reaction. Additionally, the photovoltaic property of the complex 4 was investigated. The synthesized complex $\mathbf{4}$ was used as a sensitizer in a solar cell structure. The power conversion efficiency (\%) of the complex 4 was calculated as 1.94 from the J-V curve obtained. This value shows that complex 4 can be used as an effective sensitizer in solar cell applications.

\section{References}

Abdel-Rahman L.H., et al. (2017). Synthesis, characterization, DFT calculations and biological studies of $\mathrm{Mn}$ (II), Fe (II), Co (II) and Cd (II) complexes based on a tetradentate ONNO donor Schiff base ligand. Journal of Molecular Structure, 1134, 851-862.

Altuntas I., et al. (2021). Influence of the PALE growth temperature on quality of MOVPE grown AIN/Si (111). Materials Science in Semiconductor Processing, 127, 105733.

Chen C.-Y., et al. (2009). Highly efficient light-harvesting ruthenium sensitizer for thin-film dye-sensitized solar cells. ACS Nano, 3(10), 3103-3109.

Clifford J.N., et al. (2011). Sensitizer molecular structure-device efficiency relationship in dye sensitized solar cells. Chemical Society Reviews, 40(3), 1635-1646. 
Erdoğan M. and Horoz S. (2021). Synthesis and characterization of a triphenylamine-dibenzosuberenone-based conjued organic material and an investigation of its photovoltaic properties. Journal of Chemical Research, 45(1-2), 207-212.

Erdoğan M. (2021). A novel dibenzosuberenone bridged DA- $\pi-A$ type dye: Photophysical and photovoltaic investigations. Journal of Molecular Structure, 1232, 130056.

Ferrere S. and Gregg B.A. (1998). Photosensitization of $\mathrm{TiO}_{2}$ by [Fell(2,2'-bipyridine-4,4'-dicarboxylic acid $\left.)_{2}(\mathrm{CN})_{2}\right]$ : band selective electron injection from ultra-short-lived excited states. Journal of the American Chemical Society, 120(4), 843-844.

Güngördü Solğun D., Horoz S., and Ağırtaş M.S. (2018). Synthesis of novel tetra (4-tritylphenoxy) substituted metallophthalocyanines and investigation of their aggregation, photovoltaic, solar cell properties. Inorganic and Nano-Metal Chemistry, 48(10), 508-514.

Haghverdi M., et al. (2018). Preparation, characterization, DFT calculations and ethylene oligomerization studies of iron (II) complexes bearing 2-(1H-benzimidazol-2-yl)-phenol derivatives. Journal of Coordination Chemistry, 71(8), 11801192.

Horoz S., Sahin O. and Ekinci A. (2018). Synthesis of Fe alloyed PbS thin films and investigation of their photovoltaic properties. Journal of Materials Science: Materials in Electronics, 29(16), 13442-13448.

Joseph J. and Rani G.A.B. (2014). Metal-based molecular design tuning biochemical behavior: synthesis, characterization, and biochemical studies of mixed ligand complexes derived from 4-aminoantipyrine derivatives. Spectroscopy Letters, 47(2), 86-100.

Kalyanasundaram K. and Grätzel M. (1998). Applications of functionalized transition metal complexes in photonic and optoelectronic devices. Coordination Chemistry Reviews, 177(1), 347-414.

Kapıcıoğlu A. and Esen H. (2020). Experimental investigation on using $\mathrm{Al}_{2} \mathrm{O}_{3}$ /ethylene glycol-water nano-fluid in different types of horizontal ground heat exchangers. Applied Thermal Engineering, 165, 114559.

Kushwaha A., Patil S.K., and Das D. (2018). A pyrenebenzimidazole composed effective fluoride sensor: potential mimicking of a Boolean logic gate. New Journal of Chemistry, 42(11), 9200-9208.

Mahmoud W.H., Mohamed G.G. and El-Sayed O.Y. (2018). Coordination compounds of some transition metal ions with new Schiff base ligand derived from dibenzoyl methane. Structural characterization, thermal behavior, molecular structure, antimicrobial, anticancer activity and molecular docking studies. Applied Organometallic Chemistry, 32(2), e4051.

Nazeeruddin M.K., et al. (1993). Conversion of light to electricity by cis-X2bis (2, 2'-bipyridyl-4, 4'-dicarboxylate) ruthenium (II) charge-transfer sensitizers ( $\mathrm{X}=\mathrm{Cl}-, \mathrm{Br}-, \mathrm{I}-, \mathrm{CN}-$, and $\mathrm{SCN}-$ ) on nanocrystalline titanium dioxide electrodes. Journal of the American Chemical Society, 115(14), 6382-6390.

Pinheiro D., et al. (2014). From yellow to pink using a fluorimetric and colorimetric pyrene derivative and mercury (II) ions. Dyes and Pigments, 110, 152-158.

Prasad K.S., et al. (2019). Photophysical properties and theoretical investigations of newly synthesized pyrene-naphthalene based Schiff base ligand and its copper (II) complexes. Inorganica Chimica Acta, 486, 698-703.

Rasheed L., et al. (2015). Turn-on ratiometric fluorescent probe for selective discrimination of $\mathrm{Cr}^{3+}$ from $\mathrm{Fe}^{3+}$ in aqueous media for living cell imaging. Chemistry-A European Journal, 21(46), 16349-16353.
Şahin Ö., Kilinç D., and Horoz S. (2020). A study on the ligandbound $\mathrm{Mn}$ (II) complex. Inorganic and Nano-Metal Chemistry, 50(4), 298-302.

Shellaiah M., et al. (2013). Novel pyrene-and anthracene-based Schiff base derivatives as $\mathrm{Cu} 2+$ and Fe 3+ fluorescence turnon sensors and for aggregation induced emissions. Journal of Materials Chemistry A, 1(4), 1310-1318.

Tümay S.O., et al.(2018). A systematic series of fluorescence chemosensors with multiple binding sites for $\mathrm{Hg}$ (II) based on pyrenyl-functionalized cyclotriphosphazenes and their application in live cell imaging. New Journal of Chemistry, 42(17), 14219-14228.

Yang M., Thompson D.W. and Meyer G.J. (2000). Dual pathways for $\mathrm{TiO}_{2}$ sensitization by $\mathrm{Na}_{2}$ [Fe $\left.(\mathrm{bpy})(\mathrm{CN})_{4}\right]$. Inorganic Chemistry, 39(17), 3738-3739.

Zhu X., et al. (2018). A supramolecular peptide polymer from hydrogen-bond and coordination-driven self-assembly. Polymer Chemistry, 9(1), 69-76. 